\title{
The relationship between negative and positive cognition and psychopathological states in adults aged 18 to 20
}

\section{Relation entre les cognitions négatives et positives et les états psychophysiologiques chez les adultes âgés de 18 à 20 ans}

\section{Muaweah Alsaleh*, Romain Lebreuilly, Joelle Lebreuilly, Manuel Tostain}

Center for research on risks and vulnerabilities, university of Caen, department of psychology, university of Caen-Normandy, 14000 Caen, France

Received 19 September 2015 ; received in revised form 23 February 2016; accepted 25 February 2016

Available online 29 April 2016

\section{KEYWORDS \\ Cognition; \\ Negative thinking; \\ Positive thinking; \\ Psychopathological \\ state; \\ Depression; \\ Anxiety; \\ CBT}

\begin{abstract}
Summary We have examined the relationships between positive and negative thinking and depression and anxiety. A total of 102 students have participated in this study. The Negative Automatic Thoughts Questionnaire and Positive Automatic Thoughts Questionnaire were used to evaluate negative and positive thoughts, respectively. The Beck Depression Inventory and the Beck Anxiety Inventory were used to assess psychopathological states. Depression was correlated with negative thinking $(r=0.77 ; P<0.01)$ and gender $(r=0.13 ; P<0.05)$, and inversely correlated with positive thinking $(r=-0.45 ; P<0.01)$. Multiple linear regressions showed that both negative and positive thinking affected depression $(F=148.04$ and $F=13.86$, respectively; $P<0.01)$. Anxiety was correlated with negative thinking $(r=0.62 ; P<0.01)$, and inversely correlated with positive thinking $(r=-0.31 ; P<0.01)$ and gender $(r=-0.11 ; P<0.05)$. Depressed, non-anxious participants had higher negative thinking scores $(P<0.05)$ than non-depressed, non-anxious subjects who had lower positive thinking scores $(P<0.05)$ than non-depressed, nonanxious ones. Depression and anxiety were explained by negative thinking more than positive thinking. A decrease in depression and anxiety could be linked to a decrease in negative
\end{abstract}

\footnotetext{
* Corresponding author.

E-mail addresses: moaouiya87@yahoo.com (M. Alsaleh), r.lebreuilly@free.fr (R. Lebreuilly), joelle.lebreuilly@unicaen.fr (J. Lebreuilly), manuel.tostain@unicaen.fr (M. Tostain).
} 
thoughts rather than an increase in positive thoughts. Both negative and positive thoughts may contribute to a more precise prediction of depression and anxiety levels.

(c) 2016 Association Française de Therapie Comportementale et Cognitive. Published by Elsevier Masson SAS. All rights reserved.

\section{MOTS CLÉS}

\section{Cognition ;} Pensées négatives ; Pensée positive ;

État psychopathologique ; Dépression ; Anxiété ; Thérapies comportementales et cognitives
Résumé La dépression se caractérise par la présence de pensées négatives, sur soi, sur le monde et sur l'avenir, ce que Beck a appelé la triade cognitive. Les pensées automatiques négatives sont supposées jouer un rôle central dans le développement et la persistance de la dépression (Hollon et Kendall, 1980) et de l'anxiété (Hollon et Kendall, 1980; Sanne et al., 2012). Cependant, le rôle des pensées positives dans la dépression et l'anxiété n'est pas très évident. Notre étude a pour but d'examiner le rôle des auto-déclarations négatives et positives sur le niveau d'anxiété et de dépression des étudiants. Notre échantillon se compose de 102 étudiants âgés de 18 à 20 ans, déprimés, non déprimés, anxieux et non anxieux. Les résultats de l'étude nous ont permis de mettre en évidence deux types de pensées liés aux troubles psychologiques. Premièrement, les pensées automatiques négatives sont fortement activées chez les étudiants déprimés, alors qu'elles le sont beaucoup moins chez les étudiants non déprimés. Deuxièmement, à l'inverse ce sont les pensées automatiques positives qui sont plus activées chez les étudiants non déprimés par comparaison avec les étudiants déprimés. Dans notre étude, la pensée négative est positivement corrélée avec la dépression et l'anxiété $(p<0,01)$. Cependant, la pensée positive est négativement corrélée avec la dépression et l'anxiété $(p<0,01)$. Les résultats de la régression multiple linéaire montrent que les pensées négatives et positives ont contribué de manière significative $(p<0,001)$ à expliquer la variance dans la dépression. La pensée négative a contribué de manière significative à la variance de l'anxiété $(p<0,001)$, tandis que la pensée positive $(p>0,05)$ n'a pas eu un effet significatif. Ces résultats vont dans le sens des recherches (Ingram et Price, 2010; Kendall, 1984; Kendall et Hollon, 1981), qui suggèrent que la présence de la pensée positive peut être moins importante que l'absence de la pensée négative dans la détermination des états psychopathologiques. En revanche, l'augmentation des pensées positives peut être une protection importante contre les troubles psychologiques (TPSY). Ces résultats sont cohérents avec plusieurs recherches qui indiquent que le degré de pensées positives est parfois le déterminant le plus important dans les TPSY et l'(in)adaptation psychologique (Heimberg, et al., 1985). Ainsi, les étudiants déprimés et non anxieux ont plus de pensées négatives $(p<0,05)$ et moins des pensées positives que les étudiants non déprimés et non anxieux $(p<0,05)$. Notre résultats montrent que ces pensées (PP et PN) peuvent contribuer à une meilleure compréhension des troubles psychologiques des sujets ainsi qu'au développement de traitements plus efficaces contre ces troubles, afin d'améliorer le bien-être et la qualité de vie des sujets. Cela est cohérent avec les résultats des études antérieures (Kendall et Hollon, 1981; Kendall, 1983). Enfin, la pensée négative et la pensée positive sont opposées car elles sont corrélées négativement. Il est possible pour une personne d'avoir une et/ou deux types de pensées dans une période spécifique. Cependant, les personnes ayant des pensées négatives élevées présentent de faibles pensées positives et inversement. Selon notre étude, les pensées négatives (effet fort) et les pensées positives (effet modéré à fort) peuvent contribuer à une meilleure prédiction des niveaux de dépression et d'anxiété. Les pensées positives et négatives sont des facteurs déterminants des TPSY. Plus précisément, nous pouvons dire que les PP jouent un rôle protecteur, alors que les PN jouent un rôle dévastateur. Cette étude suggère que le manque de PP peut, ne pas être seulement, qu'un épiphénomène de la dépression et de l'anxiété. Elle permet de se rendre compte qu'un manque de PP est tout aussi important que la présence ou le développement d'une quantité excessive de PN. Ces pensées automatiques positives n'ont pas seulement pour but de limiter les émotions et les comportements négatifs, elles permettent aussi d'aider les sujets à éprouver davantage de bien-être. C'est l'objectif principal des recherches sur les thérapies comportementales et cognitives (TCC), aujourd'hui très actives en psychologie, notamment en psychologie cognitive. Notre recherche confirme l'utilité de la mise en place des outils de la TCC dans le cadre de la prévention des troubles anxieux et dépressifs dans la population étudiante où les pratiques de soins sont peu développées actuellement.

(c) 2016 Association Française de Therapie Comportementale et Cognitive. Publié par Elsevier Masson SAS. Tous droits réservés. 


\section{Introduction}

Cognition is the way we think about ourselves. Automatic thoughts are explored in several theories dealing with psychopathology [1]. Several authors have placed increasing emphasis on the role of cognition in the origin, maintenance, and treatment of different types of psychopathology [2,3]. Haaga, Dyck, and Ernst [4] pointed out that this theoretical position focused on the automatic negative cognitions encountered in psychological disorders, whilst others $[1,5]$ postulated that a specific relationship between positive and negative cognition might be a key determinant in psychopathology. Kendall suggested that examination of both negative and positive cognitions could contribute to a better understanding of the health-pathology relationship [5]. In addition, other authors have reported that a positive cognition deficit could be a facet of emotional disorders, which is as influential as excessive negative cognition $[6,7]$. Cognition plays an important role in theories concerning the development and treatment of psychopathologies such as anxiety disorders, depression, and loss of self-esteem. Beck [2] was amazed to discover the extent to which his patients' cognitions affected both their feelings and their behaviour, and thus possibly their well-being.

Automatic thoughts are the "stream of thoughts, ideas and images which constantly accompany an individual as he or she proceeds through daily life"' [8]. As the most superficial level of cognition, it plays a critical role in CBT because it directly influences our emotions and behavior [9]. These thoughts are often easily accessible and frequently susceptible to modification, and are considered to be the output of our information processing system-the product of how people construct and perceive their worlds [1]. Automatic thoughts are regarded as automatic because they can be initiated by both conscious and unconscious thoughts, and the cognitive processes that follow do not require conscious effort [1]. Cognitive models of psychopathology [2] posit that dysfunctional cognitions directly contribute to negative emotions. Accordingly, a common technique in traditional cognitive-behavioral therapy (CBT) is cognitive restructuring [10]. The goal of this process is to encourage patients to think in more accurate and adaptive ways, which facilitate effective problem solving and living a more satisfying life $[11,12]$.

Negative thinking has been found to play a pivotal role in psychopathological states such as depression [3,11,13-18] and anxiety $[3,7,17-21]$. Indeed, studies have found a connection between the presence of negative thoughts and anxiety in clinically anxious adults [22] and children [23]. Conversely, positive thinking has been found to be negatively related to psychopathological states including depression $[1,13,14,17,24]$ and anxiety [17].

Cognition themes in depressed and/or anxious individuals are characterized by a loss of self-esteem, self-blame, self-criticism, and a desire to escape and commit suicide. According to Beck, depressed patients tend to distort their experiences in an idiosyncratic way [2]. Ingram and Wisnicki [25] proposed that the presence of positive thinking may be less important in determining psychopathological states than the absence of negative thinking $[5,26]$. However, when focusing on positive psychology $[27,28]$, a second view holds that the presence of positive thinking rather than the presence of negative thinking may be more important in determining both psychopathological states and well-being [7].

In studies examining the cognitive model in student samples, the main focus has been on negative rather than on positive thinking. Kendall, 1984 [7] observed that psychological adjustments might not be related as so much to positive thinking, but to the absence of negative thinking. In addition, he reported that improvements in psychopathological states were linked to a reduction in negative thoughts rather than an increase in positive thoughts. This phenomenon has been called the "Power of Non-negative Thinking" [23]. Thoughts play an important role in the cognitive model of development and treatment of psychopathological states such as anxiety disorders, depression, and loss of selfesteem. Cognitive therapy is based on the cognitive model and focuses on identifying and restructuring biased negative thoughts and interpretations. The cognitive model was originally developed for adults and assumes that anxious and depressed individuals process external and internal stimuli in a biased way, resulting in a variety of cognitive errors (e.g. over-generalization, personalization, selective abstraction, etc.) [29].

The central question is therefore to determine the extent to which anxiety and depression can be related to recurrent negative thinking as opposed to a deficit of positive cognition. The purpose of this study was to attempt to identify the link between negative thinking versus positive thinking and several important psychological variables indicative of one's psychopathological state (e.g., depression, anxiety) in adults aged between 18 and 20 years old in a Caen University (France) student sample.

Our main hypothesis was that negative thinking (NT) would be positively correlated with depression and anxiety, and our alternate hypothesis was that positive thinking (PT) would be inversely correlated with depression and anxiety.

\section{Method}

\section{Participants}

One hundred and two male and female undergraduate students at the University of Caen aged 18-20years old participated in this study. Participation was voluntary and responses were anonymous. The 18-20-year-old narrow age window was selected to control the impact of age on the study's variables.

\section{Measures}

Participants' thoughts have been evaluated at the beginning of their first year of undergraduate studies.

\section{Negative Automatic Thoughts Questionnaire (ATQ-N)}

The Negative Automatic Thoughts Questionnaire (ATQ-N) [3] was designed to measure the frequency of negative thoughts. These negative thoughts are believed to play 
an important role in the development, maintenance, and treatment of various types of psychological maladjustment, including depression [11] and anxiety [19]. The thirty items of the ATQ-N are scored on a 5-point scale: 1 = Not at all, 2 = Sometimes, 3 = Moderately often, 4 = Often, $5=$ Permanently (Always). The total score is a sum of all the thirty items. The ATQ is reported to have an excellent internal consistency and good concurrent validity for depression [3].

The ATQ [3] is one of the most widely used instruments for measuring automatic thoughts [30]. The original ATQ-30 was designed to measure the frequency of negative automatic thoughts associated with depression [3,31]. Research has demonstrated the ATQ's discriminate validity for differentiating between depressed and non-depressed groups [3,32]. Numerous studies have supported the convergent validity of the ATQ via its positive correlation with various measures of depression [33,34] and anxiety symptoms [35] and its negative correlation with life satisfaction [36]; studies have also shown support for predictive validity because of its ability to significantly predict the onset of suicidal ideation 3 months later [37].

Automatic Thoughts Questionnaire (ATQ) [3], which has been developed to assess spontaneous negative selfstatements and intrusive cognitions as experienced by depressed persons. To that end, adults (college students) were asked to recall depressing situations and then to list their spontaneous thoughts in those situations. The ATQ consists of items that discriminated depressed and nondepressed persons. Construct validity of the ATQ has been supported by findings that depressed and non-depressed adults, whether clinic or non-clinic samples [31].

\section{Positive Automatic Thoughts Questionnaire (ATQ-P)}

The ATQ-P [25] was developed as the theoretical complement to the ATQ-N. The ATQ-P is a thirty-item self-report instrument that measures the frequency of positive thoughts. The thirty items on the ATQ-N are scored on a 5-point scale: 1 = Not at all, 2 =Sometimes, $3=$ Moderately often, $4=$ Often, 5 = Permanently. The total score is the sum of all the thirty items. The ATQ-P is reported to be reliable, capable of differentiating between psychopathological and non-psychopathological states and it is unaffected by social desirability influences. In addition, this scale has good convergent and discriminatory power and is sensitive to changes in affective states [1].

Automatic thoughts may include both negative and positive thinking. Ingram and Wisnicki [25] have developed a 30-item Positive Automatic Thought Questionnaire (ATQ-P) to measure positive automatic thoughts as a complement to the ATQ. Like the ATQ, the ATQ-P also showed adequate internal consistency [25] and good test-retest reliability over 9 weeks [1]. ATQ-P were positively correlated with positive affect, and negatively correlated with negative affect and depressive and anxiety symptoms [16].

\section{Beck Depression Inventory, abbreviated form, BDI-13}

The 13-item Beck Depression Inventory (BDI-13) is a selfreporting instrument that assesses depressive symptoms.
Each item contains four statements reflecting various degrees of symptom severity. Participants are instructed to circle the number (ranging from zero to three, indicating severity) corresponding to the statement that best describes them. The total BDI-13 score ranges from 0 to 39. The BDI-13 has demonstrated high internal consistency, good test-retest reliability, and good construct and concurrent validity with other common depression scales in clinical and non-clinical samples [38]. Compared to the original version, the short version differentiates depressed from nondepressed subjects and non-depressed-anxious subjects, but it does not distinguish between anxious-depressed from nonanxious-depressed subjects [39]. Participants were declared depressed if they had a score $\geq 4$ on the BDI-13 scale.

\section{Beck Anxiety Inventory (BAI)}

The BAI [40] is a 21-item and self-reporting inventory for measuring severity of anxiety. Respondents are instructed to circle the number representing one of the four alternatives, which ranges from no anxiety $(1=$ Not at all) to severe anxiety ( 4 = severely or "I could barely stand it"). The total BAl score ranges from 21 to 84 . The BAl demonstrated high internal consistency and test-retest reliability and good concurrent and discriminatory validity [40]. Moreover, the BAI was carefully constructed to avoid confusion with depression. Participants were declared anxious if they had a score $\geq 43$ on the BAl scale.

\section{Procedure and data analysis}

Before completing the ATQ-N, ATQ-P, BDI and BAI, participants were asked to read instructions about filling in the questionnaire. The study received approval from the Psychology department's Human Research unit (CERReV, MRSH) at Caen University (France).

The data were summarized by standard descriptive statistics and correlation analyses. The Student t-test has been used for depressed, non-anxious and non-depressed, nonanxious participants. Three sets of multiple linear regression analyses have been defined for each of the two dependent variables (depression and anxiety): Forward, Backward, Stepwise, while using the same three predictors for gender, positive thinking, and negative thinking (automatic thoughts) in each analysis.

The SAS and R software (Version 9.3, SAS Institute Inc., Cary, NC; Version R x64 3.2.0) has been used to perform multiple linear regression analyses.

\section{Results}

\section{Descriptive statistics of the sample}

The sample consisted of 102 students with a mean age of 18.6 and a standard deviation of $0.7 .88(86.3 \%)$ were female and $14(13.7 \%)$ were male. The mean and standard deviation (SD) scores for negative thinking, positive thinking, depression, and anxiety are shown in Table 1. 
Table 1 Descriptive statistics of the sample. Statistiques descriptives de l'échantillon.

\begin{tabular}{llrr}
\hline Variable & $n$ & Mean & \multicolumn{1}{c}{ SD } \\
\hline Age & 102 & 18.64 & 0.73 \\
Gender, $n$ (\%) & & & \\
$\quad$ Male & $14(13.7)$ & & \\
$\quad$ Female & $88(86.3)$ & & \\
Negative thinking & 102 & 48.32 & 15.32 \\
Positive thinking & 102 & 86.82 & 20.35 \\
Depression & 102 & 4.92 & 4.30 \\
Anxiety & 102 & 29.16 & 7.10 \\
\hline
\end{tabular}

\section{Overall correlations}

The correlation coefficients were reported in Table 2. Gender was significantly correlated with depression and anxiety $(r=0.13$ and $r=-0.11$, respectively; $P<0.05)$; these correlations were a negligible relationship, according the criteria $r$. Negative thoughts have been inversely correlated with positive thoughts $(r=-0.30 ; P<0.01)$; this correlation was a moderate negative relationship. Depression was positively correlated with anxiety $(r=0.62 ; P<0.01)$; this correlation was a strong positive relationship.

\section{Thinking and depression}

Depression was positively correlated with negative thinking ( $r=0.77 ; P<0.01)$; this correlation was a higher, very strong positive relationship. Depression was also positively correlated with gender $(r=0.13 ; P<0.05)$; this correlation was a negligible relationship. Finally, depression was inversely correlated with positive thinking $(r=0.45 ; P<0.01)$; this correlation was a strong negative relationship, in a decreasing order of magnitude (see Table 2).

The two variables (depression and negative thinking) increase or decrease together because they have a positive correlation, but increases in one variable, such as positive thinking, are associated with decreases in the other, such as depression, because they have a negative correlation.

The effect size between depression and NT is large because it is greater than 0.50, the effect size between depression and gender is small because it is near 0.10 , and the effect size between depression and PT is large because it is near 0.50 , according to Cohen's guidelines for the social sciences.

Multiple linear regression analyses have shown that both negative thinking and positive thinking had a statistically significant effect on depression $(P<0.001)$ after controlling for age. Gender did not affect depression (Table 3).

Concerning depression, adjusted $R^{2}$ between gender, age, NT, PT, and depression (Adj. $R^{2}$ ) $=0.64$, which means that $64 \%$ of the total variation in depression can be explained by the linear relationship between gender, age, NT, PT, and depression. This adjusted R2 was smaller than multiple $R^{2}$ and was the best estimate of the degree of relationship in the underlying population (Table 3). Also the model was significant with a $P$-value of $2.2 \mathrm{e}^{-16}$. $P$-values for NA $(0.0001<0.05)$ and PA $(0.0001<0.05)$ were less than 0.05 , which has shown that this result was significant (i.e. NA and PA can really explain depression), while $P$-values for age $(0.77>0.05)$ and sex $(0.17>0.05)$ were higher than 0.05 , which means that the result was not significant.

\section{Thinking and anxiety}

Anxiety was significantly correlated with negative thinking $(r=0.62 ; P<0.01)$. This correlation was a strong positive relationship, and inversely correlated with positive thinking $(r=-0.31 ; P<0.01)$, which was a moderate negative relationship, and gender $(r=-0.11 ; P<0.05)$, which was a negligible relationship in decreasing order of magnitude (Table 2).

The two variables (anxiety and negative thinking) increase or decrease together because they have a positive correlation, but increases in one variable, such as positive thinking, are associated with decreases in the other, such as anxiety, because they have a negative correlation.

The effect size between anxiety and NT is large because it is greater than 0.50 , the effect size between anxiety and gender is small because it is near 0.10 , and the effect size between anxiety and PT is medium because it is near 0.30 , according to Cohen's guidelines for the social sciences.

Multiple linear regression analyses have shown that negative thinking $(P<0.001)$ and gender $(P<0.05)$ significantly affect anxiety after controlling for age. Positive thinking $(P>0.05)$ did not have a statistically significant effect on anxiety (Table 4).

Table 2 Multiple correlation coefficients for the different combinations. Coefficients des corrélations pour les différentes variables.

\begin{tabular}{|c|c|c|c|c|c|c|}
\hline Measure & Age & Gender & NT & PT & Depression & Anxiety \\
\hline Age & - & 0.00 & -0.02 & -0.07 & -0.01 & 0.02 \\
\hline Gender & & - & 0.08 & 0.01 & $0.13^{*}$ & $-0.11^{*}$ \\
\hline NT & & & - & $-0.30^{* *}$ & $0.77^{* *}$ & $0.62^{* *}$ \\
\hline PT & & & & - & $-0.45^{* *}$ & $-0.31^{k *}$ \\
\hline Depression & & & & & - & $0.62^{* *}$ \\
\hline Anxiety & & & & & & - \\
\hline
\end{tabular}


Table 3 Summary of multiple linear regression analyses for variables predicting depression. Résumé de l'analyse de régression linéaire multiple pour les variables prédisant la dépression.

\begin{tabular}{llclrr}
\hline Step & Variable & Estimate & Standard error & $t$-value & $\operatorname{Pr}(>|\mathrm{t}|)$ \\
\hline 1 & Age & -0.104 & 0.3540 & -0.294 & 0.769 \\
2 & Gender & 1.038 & 0.746 & 1.392 & 0.167 \\
3 & Negative thinking & 0.195 & 0.017 & 11.019 & $P<0,00001$ \\
4 & Positive thinking & -0.050 & 0.013 & -3.780 & $P<0.00001$ \\
\hline
\end{tabular}

Residual standard error: 2.584 on 97 degrees of freedom; multiple $R^{2}: 0.6536$; adjusted $R^{2}: 0.639 ; F$-statistic: 45.75 on 4 and 97 DF; $P$-value: $<0.0001$.

Table 4 Summary of multiple linear regression analyses for variables predicting anxiety. Résumé de l'analyse de régression linéaire multiple pour les variables prédisant l'anxiété.

\begin{tabular}{lllllc}
\hline Step & Variable & Estimate & Standard error & $t$-value & Pr $(>|\mathrm{t}|)$ \\
\hline 1 & Age & 0.252 & 0.754 & 0.334 & 0.739 \\
2 & Gender & -3.231 & 1.591 & -2.031 & $0.04^{*}$ \\
3 & Negative thinking & 0.274 & 0.037 & 7.270 & $P<0.00001$ \\
4 & Positive thinking & -0.043 & 0.028 & -1.524 & 0.131 \\
\hline
\end{tabular}

Residual standard error: 5.511 on 97 degrees of freedom; multiple $R^{2}: 0.421$; adjusted $R^{2}: 0.397 ; F$-statistic: 17.67 on 4 and $97 \mathrm{DF}$; $P$-value: $<0.00001$.

Concerning anxiety, adjusted $R^{2}$ between gender, age, NT, PT, and anxiety (Adj. $\left.R^{2}\right)=0.40$, which means that $40 \%$ of the total variation in anxiety can be really explained by the linear relationship between gender, age, NT, PT, and anxiety (Table 4). Also the model was significant, with a $P$-value of $6.359 \mathrm{e}^{-11}$. The $P$-values for NA $(0.0001<0.05)$ were less than 0.05 , which showed that this result was significant (i.e. NA can explain anxiety), and the $P$-values for gender $(0.04<0.05)$ were less than 0.05 , which showed that this result was significant (i.e. gender can really explain anxiety), while the $P$-values for age $(0.73>0.05)$ and PT $(0.13>0.05)$ were greater than 0.05 , which means that the result was not significant.

\section{Negative thinking and positive thinking in depressed and anxious participants}

The average negative thinking (NT) and positive thinking (PT) scores distributed as a function of depression and anxiety are shown in Table 5. Participants were broken down into four categories: depressed anxious, depressed non-anxious, anxious non-depressed, and non-depressed non-anxious, and both variables, NT, and PT, were examined in each of these groups. Participants were considered to be depressed if they had a BDI-13 score $\geq 4$ and anxious if the BAl score $\geq 43$. According to the mean values for each category, depressed anxious participants had more negative thinking and less positive thinking than depressed non-anxious subjects, while depressed non-anxious participants had more negative thinking and less positive thinking than non-depressed, non-anxious ones. In our sample, there were no anxious, non-depressed participants (Table 5). The results showed that negative thinking scores in depressed, non-anxious participants were significantly greater than in the non-depressed, non-anxious participants $(t(98)=5.78 ; P<0.05)$, and that positive thinking scores in the depressed, non-anxious participants were significantly lower than in non-depressed, non-anxious participants $(t(98)=-2.96 ; P<0.05)$.

In conclusion, the NT score was always higher in depressed than in non-depressed adults and in depressed

Table 5 Mean and standard deviations of negative thinking and positive thinking scores according to depressive and anxious states.

Moyenne et écarts-types les scores de la pensée négative et de la pensée positive selon les états dépressifs et anxieux.

\begin{tabular}{|c|c|c|c|c|c|}
\hline \multirow[t]{2}{*}{ Participants } & \multicolumn{2}{|c|}{ Negative thinking } & \multicolumn{2}{|c|}{ Positive thinking } & \multirow[t]{2}{*}{$n$} \\
\hline & Mean & SD & Mean & SD & \\
\hline Depressed anxious & 91.50 & 44.55 & 59.50 & 13.44 & 2 \\
\hline Depressed non-anxious & 52.74 & 14.05 & 82.87 & 19.34 & 62 \\
\hline Anxious non-depressed & - & - & - & - & 0 \\
\hline Non-depressed non-anxious & 38.84 & 5.97 & 94.71 & 19.46 & 38 \\
\hline Total & & & & & 102 \\
\hline
\end{tabular}


Sex and Negative thinking

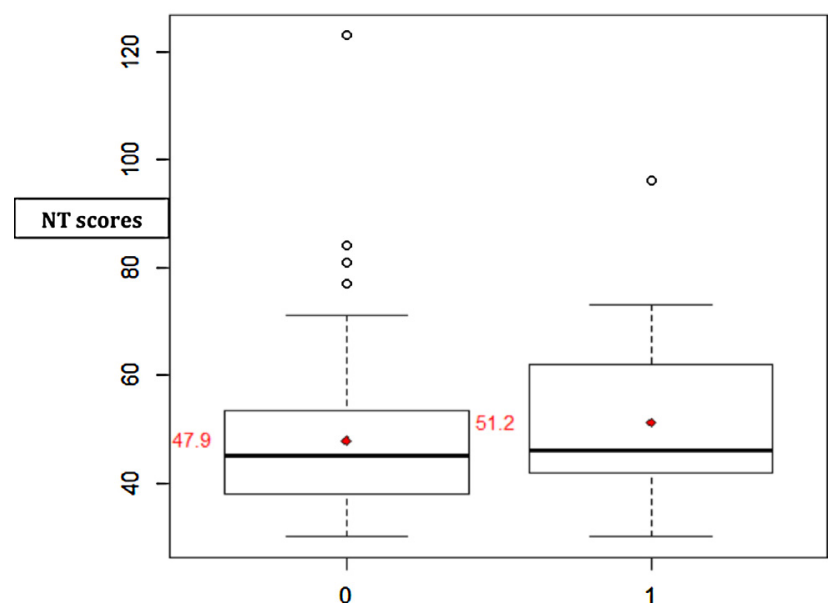

Figure 1 Sex and NT $-1=$ women; $0=$ men. According to sex, NT means are the numbers next to the boxplot.

Le sexe et $P N-1=$ femmes; $0=$ hommes. Selon le sexe, les moyennes de la PN sont les numéros à côté de la boîte à moustaches.

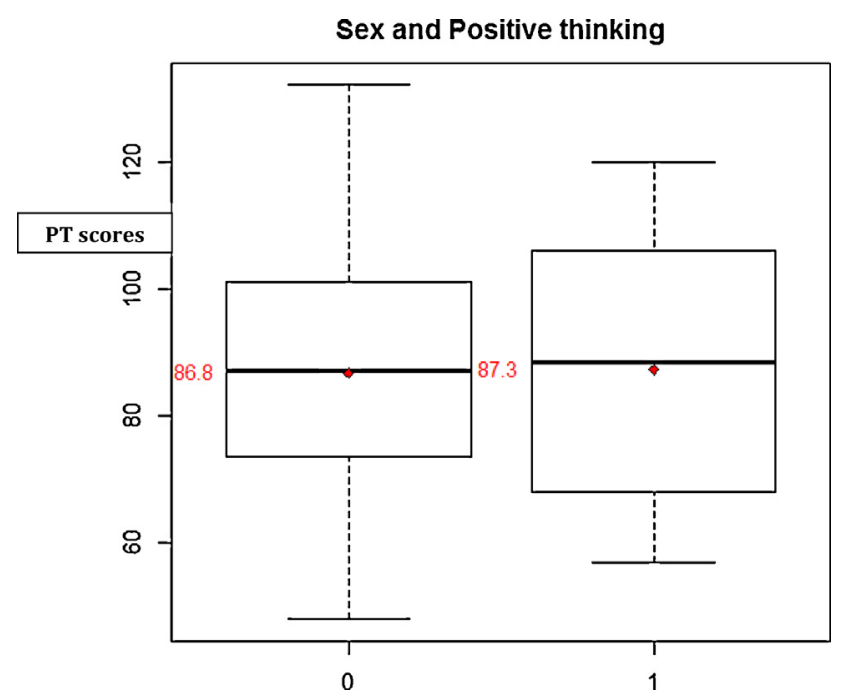

Figure 2 Sex and PT $-1=$ women; $0=$ men. According to sex, PT means are the numbers next to the boxplot.

Le sexe et $P P-1=$ femmes; $0=$ hommes. Selon le sexe, les moyennes de la PP sont les numéros à côté de la boîte à moustaches.

anxious subjects than in depressed, non-anxious and nondepressed, non-anxious adults. In contrast, the PT score was always higher in non-depressed than in depressed adults and in non-depressed, non-anxious participants than in depressed, non-anxious and depressed anxious adults.

\section{Gender, NT, and PT}

The result has shown that the males (value 0 ) did not have a greater NT and PT than the females (value 1) (Figs. 1 and 2).

In addition, the mean population has a 95\% chance of being comprised between 45.2862 and 51.3538 (confidence intervals $=6.0676$, and $1 / 2$ confidence intervals $=3.0338$ ).

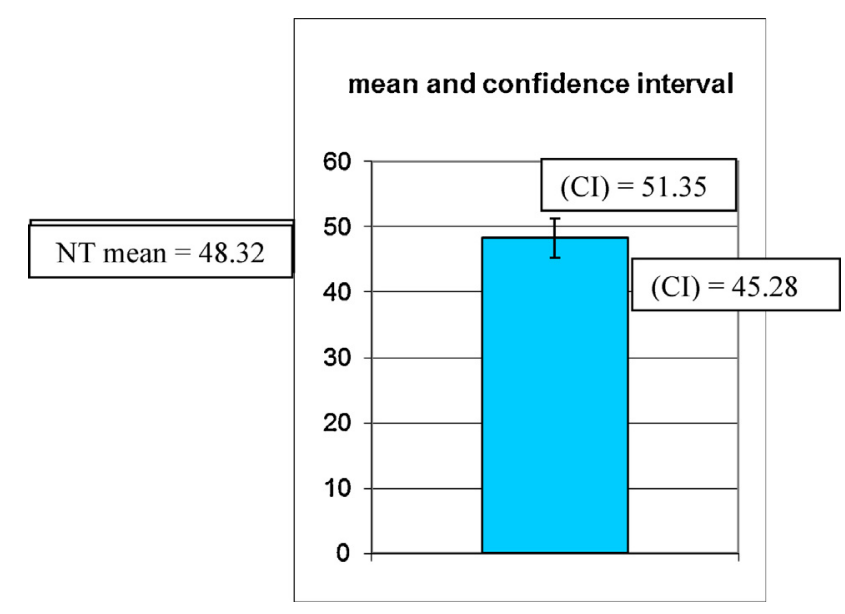

Figure 3 The confidence interval $(\mathrm{Cl})$ of a NT mean. L'intervalle de confiance (IC) de la moyenne de la PN.

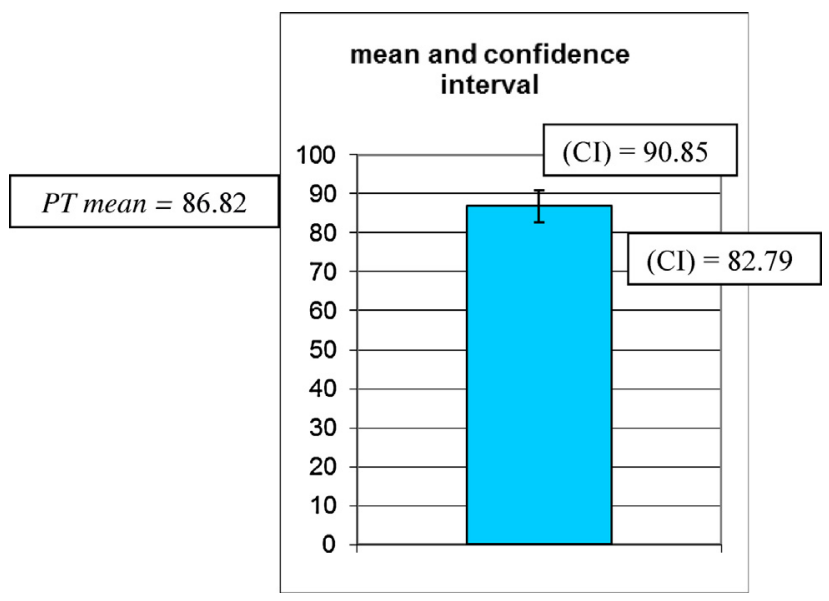

Figure 4 The confidence interval of a PT mean.

L'intervalle de confiance (IC) de la moyenne de la PP.

This means that, if the degree of confidence is 95\% (Fig. 3), the mean NT score of the student community aged between 17 and 29 years old is between 45.2862 (the minimum level) and 51.3538 (the maximum level), whereas $5 \%$ are located outside of these two levels.

The mean population has a $95 \%$ chance of being comprised between 82.7901 and 90.8499 (confidence intervals $=8.0598$, and $1 / 2$ confidence intervals $=4.0299)$. This means that, if the degree of confidence is $95 \%$ (Fig. 4), the mean of the PT score of the community of students aged between 17 and 29 is between 82.7901 (minimum level) and 90.8499 (maximum level), whereas 5\% are located outside of these two levels.

\section{Gender, depression, and anxiety}

The result has shown that the females (value 1) exhibit more depression than the males (value 0) (Fig. 5). The result has shown that the females (value 1) exhibit less anxiety than the males (value 0) (Fig. 6).

In addition, the mean population has a 95\% chance of being comprised between 4.0685 and 5.7715 (confidence 


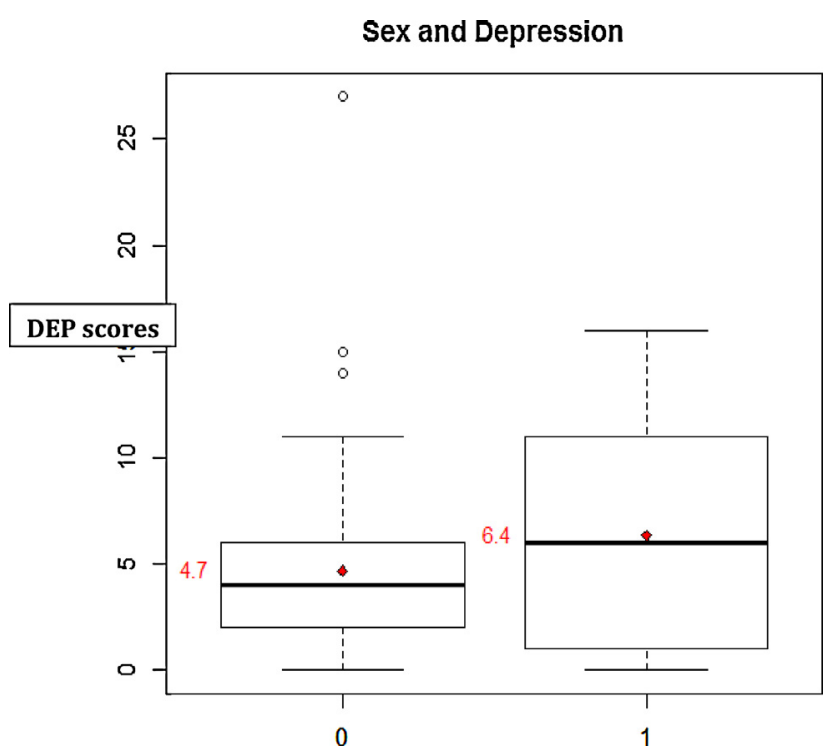

Figure 5 Sex and depression $-1=$ women; $0=$ men. According to sex, DEP means are the numbers next to the boxplot. Le sexe et la dépression-1=femmes; $0=$ hommes. Selon le sexe, les moyennes de la DEP sont les numéros à côté de la boîte à moustaches.

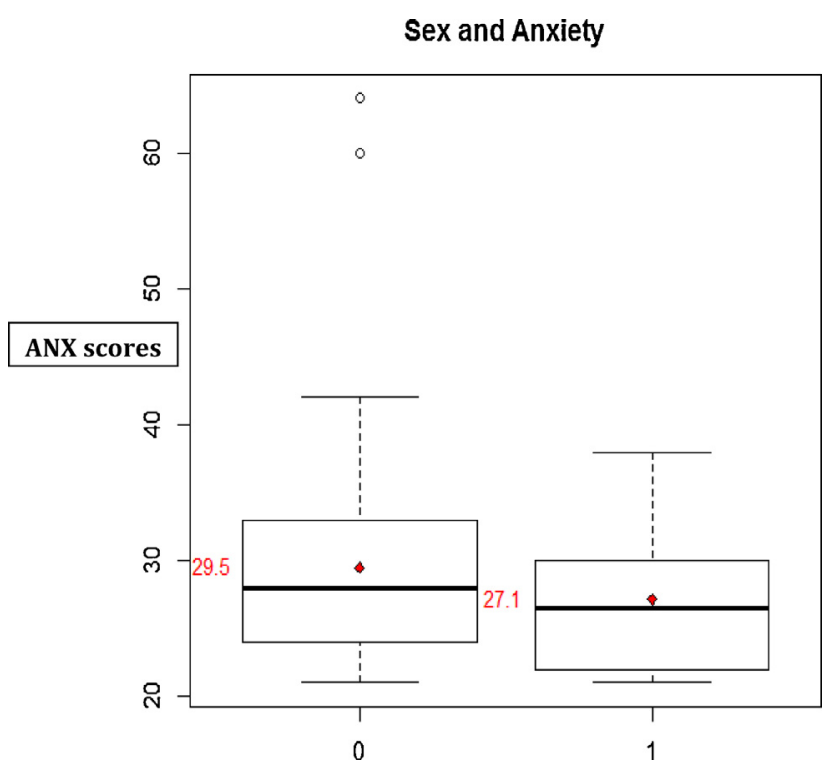

Figure 6 Sex and anxiety $-1=$ women; $0=$ men. According to sex, ANX means are the numbers next to the boxplot.

Le sexe et l'anxiété -1 =femmes; 0 =hommes. Selon le sexe, les moyennes de l'ANX sont les numéros à côté de la boîte à moustaches.

intervals $=1.7031$, and $1 / 2$ confidence intervals $=0.8515$ ) This means that, if the degree of confidence is $95 \%$ (Fig. 7), the mean depression score of the student community aged between 17 and 29 years old is between 4.0685 (minimum level) and 5.7715 (maximum level), whereas $5 \%$ are located outside of these two levels.

In addition, the mean population has a $95 \%$ chance of being comprised between 27.7540 and 30.5660 (confidence intervals $=2.8120$, and $1 / 2$ confidence intervals $=1.4060$ ).

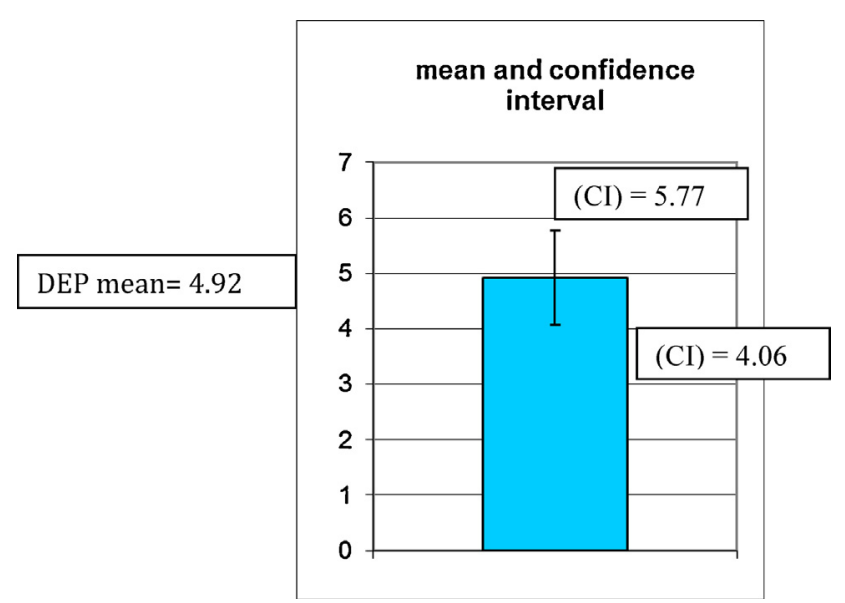

Figure 7 The confidence interval of a depression mean. L'intervalle de confiance (IC) de la moyenne de la dépression.

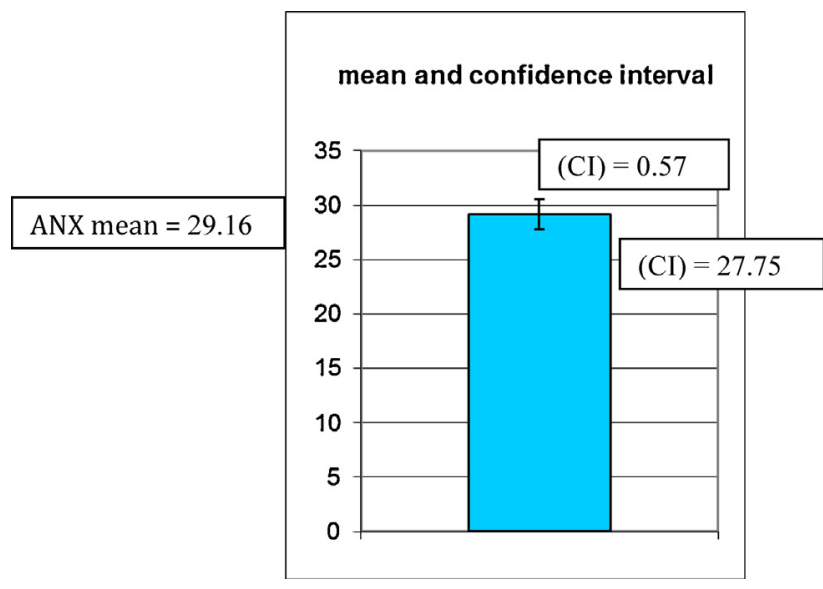

Figure 8 The confidence interval of an anxiety mean. L'intervalle de confiance (IC) de la moyenne de l'anxiété.

This means that, if the degree of confidence is 95\% (Fig. 8), the mean anxiety score of the student community aged between 17 and 29 years old is between 27.7540 (minimum level) and 30.5660 (maximum level), whereas $5 \%$ are located outside of these two levels.

\section{Discussion}

The purpose of our study was to identify the link between cognitive dimensions (both negative and positive cognition) and several important psychological variables indicative of psychopathological states in young adults aged between 18 and 20 years old in a Caen University student sample. The study has focused on negative and positive thinking and their relationships with psychopathological states, especially depression and anxiety. Our hypothesis was that negative thinking would be positively correlated with depression and anxiety, and our alternate hypothesis was that positive thinking would be negatively correlated with depression and anxiety.

Age was not significantly predictive of any of the variables; this may be due, at least in part, to the narrow age range selected (18-20years). The explanatory role of 
gender was relatively minor compared to negative thinking and positive thinking. This means that males were as likely as females to think both negatively and positively. In compliance with previous findings [41], our results have shown that gender was significantly $(P<0.05)$ correlated with both depression and anxiety, but this correlation was a negligible relationship, according the criteria $r$.

Multiple linear regression analyses have shown that the gender effect was not significant in comparison with both types of thinking $(P<0.001)$ in depression, but was significant $(P<0.001)$ in comparison with positive thinking in anxiety. These results stress the importance of exploring factors beyond gender and age when explaining individual differences in psychopathological states (depression and anxiety). In addition, these results have underlined the importance of examining negative cognition to explain psychological disorders.

Correlation analyses support our hypotheses that negative thinking was positively correlated with psychopathological state scores for anxiety and depression, while the opposite was observed for positive thinking, which was negatively correlated with psychopathological state scores for anxiety and depression. The correlations obtained were consistent with the theoretical expectations as well as previous findings $[1,4,11,17,18]$. Like some other studies $[11,17,18,20,24,42]$, our study showed that negative thinking was positively linked with depression and anxiety.

The multiple linear regression analyses support our hypothesis for depression but not for anxiety. Our results were similar to those of previous studies $[3,13,14,17,18,20,24]$ as negative thinking was positively correlated with depression and anxiety. However, our alternate hypothesis was only partially verified, as positive thoughts correlated significantly with depression, but not on anxiety. The multiple linear regression results showed that both negative and positive thinking significantly contributed $(P<0.001)$ to explain the variance in depression after controlling for age, but gender had no effect. Conversely, negative thinking significantly contributed $(P<0.001)$ to the variance in anxiety, while positive thinking did not have a significant effect. This result is consistent with previous proposals $[5,26,43]$, suggesting that the presence of positive thinking may be less important than the absence of negative thinking in determining psychopathological states.

Concerning depression, the correlation coefficient between NT and depression was $r=0.77$, so that $r^{2}=0.5929$, which means that $59 \%$ of the total variation in depression can be explained by the linear relationship between NT and depression. The correlation coefficient between PA and depression was $r=-0.45$, so that $r^{2}=0.2025$, which means that $20 \%$ of the total variation in depression can be explained by the linear relationship between PT and depression. These results have shown that the NT could better explain depression than PT.

Concerning anxiety, the correlation coefficient between NT and anxiety was $r=0.62$, so that $r^{2}=0.3844$, which means that $38 \%$ of the total variation in anxiety can be explained by the linear relationship between NT and anxiety. The correlation coefficient between PT and anxiety was $r=-0.31$, so that $r^{2}=0.0961$, which means that $9.6 \%$ of the total variation in anxiety can be explained by the linear relationship between PT and anxiety. These results have shown that the NT could better explain anxiety than PT.

The results have shown that there is no difference between gender (males and females) concerning positive and negative thinking. But the results showed that there is difference between males and females concerning anxiety. The results also showed that there is difference between genders concerning depression.

This study had several implications. Our results underlined that, in our study, negative thinking was relatively more important than positive thinking in explaining psychopathological states and disorders such as depression and anxiety. This is consistent with the findings of Haaga et al., [4] who suggest that the presence of negative thinking outweighs positive thinking in determining psychopathological states.

This means that positive thinking alone may not offer sufficient protection against depression and anxiety. Therefore, it is also consistent with the "power of non-negative thinking" suggested by a number of theorists [23]. The severity of the depression and/or anxiety may play an important role in determining the frequency of negative and/or positive thinking. In the current non-clinical sample, we found that the presence of positive thinking better explained the variance in depression and anxiety than negative thinking. Firstly, we can suppose that this also means that the reduction in depression and anxiety could be linked to an increase in positive thoughts rather than a decrease in negative thoughts. In the second time, it must pass for the NT (this also means that the reduction in depression and anxiety could be linked to a decrease in negative thoughts).

Our study has several limitations. First, as the study was conducted in a sample of young and presumably healthy university students, our findings cannot be generalized to clinical populations. Secondly, we mainly focused on cognitive content (i.e. expressed thoughts), leaving out cognitive processes and other components of the cognitive model (e.g. coping ability or cognitive coping). Further studies using clinical and/or non-clinical samples are needed to confirm our results. Another possible limitation was also related to the single measurement of the psychological state of participants; further studies could be performed to achieve a higher reliability with repeated measurements, taking into account the learning curve for depression and anxiety scales.

Our results showed that depressed, non-anxious adults had more negative thoughts and less positive thoughts than non-depressed, non-anxious adults. These results are consistent with the negativity hypothesis [4], which states that depressed people have more depressed thoughts than nondepressed people. Our results are also consistent with the positivity hypothesis, which holds that non-depressed, nonanxious adults' thoughts may be more positive than those of depressed, non-anxious adults. We found support for the role of negative thoughts in adults' anxiety and depression; depressed and/or anxious adults reported more negative thoughts than non-anxious and non-depressed adults. Depressed and anxious adults also reported less positive thoughts than non-depressed and non-anxious adults. One possible factor in CBT's effectiveness in treating depression is that depression is characterized by enhanced negative information processing $[2,44]$. Depressed persons have 
frequent negative automatic thoughts about themselves, their future, and the world [45]; these automatic thoughts induce depressive mood states in the cognitive model of depression. Hollon and Kendall [3] found that persons with depression showed significantly greater numbers of negative automatic thoughts than non-depression persons. Therefore, for CBT to be effective in treating depressive symptoms, it is important that automatic thoughts become more functional and positive [46]. The effectiveness of treating depression with cognitive-behavioral therapy (CBT) has been substantiated by a growing number of clinical intervention studies $[47,48]$.

Finally, negative and positive thinking have opposite natures since they are negatively correlated. It is possible for one individual to have one and/or both types of thinking within a specific period of time. However, individuals with high negative thinking do have low positive thinking, and vice versa. According to this study, both negative thoughts (large effect) and positive thoughts (small effect) may contribute to better predicting depression and anxiety levels.

\section{Automatic Thought in Cognitive-Behavioral Therapy (CBT)}

CBT is a highly effective treatment for a wide range of mental $[12,49]$. Cognitive-behavioral researchers have also recognized that the assessment of positive and negative cognitions may contribute to a better understanding of psychopathology and the development of more effective treatments $[43,50]$. Cognitive processes have been accorded a pivotal role in the etiology, treatment, maintenance, and remission of depression [51-53]. Cognitions play an important role in theories about the development and treatment of anxiety disorders [21]. Often activated by negative and stressful life events, negative automatic thoughts are often repetitive and intrusive, which play a key role in precipitating psychopathology [54]. Negative automatic thoughts are specific in content and unique to different psychological disorders [55], such as depression [56] and anxiety [35]. In CBT, negative automatic thoughts have a causal role in the onset of negative mood and depressive symptoms [9]. In contrast, positive automatic thoughts may act as a buffer against significant distress [25].

\section{Research and Practice Implications of positive automatic thoughts for Cognitive-Behavioral Therapy (CBT)}

With the increasing number of French people suffering from psychological distress and various mental health problems, a questionnaire form of the ATQ including the evaluation of both positive and negative automatic thoughts could be used as a useful alternative in large-scale research and clinical assessments in which multiple constructs are measured. In this sense, the ATQ-P-N, with its satisfactory reliability and convergent validity, is an easy-to-use scale that can be applied in both research and clinical settings. Furthermore, in the clinical assessment of mental health problems for French clients, the ATQ-P-N could be a useful supplement to current mental health measures, especially for assessing depression and anxiety. Cognitive assessment can be a useful reference not only for clinical diagnosis but also for the treatment evaluation of CBT. These automatic thought questionnaires for French people would also advance the research of CBT in French communities. Specific culturally sensitive CBT intervention may be helpful for this population, such as cognitive restructuring of negative thoughts related to depression, anxiety and states of mind [57]. With an assessment tool, researchers would be able to evaluate the effectiveness of CBT for French clients and explore the relationship between cognitive change and mental health outcome measures.

\section{Non-clinical Implications}

It should be noted that this study was correlational and that the author did not assess the temporal precedence of positive and negative thinking, depression, and anxiety. This study showed that NT and PT can help to explain depression and NT can help to explain anxiety; gender can help to explain anxiety but cannot help to explain depression. This study suggests that a lack of PT may not only be an epiphenomenon of anxiety and depression. Although more research is needed, it cannot be ruled out that a lack of PT is equally important in the development or presence of an excessive amount of NT.

To conclude, in this study an emotion questionnaire was used to simultaneously measure the amount of negative and positive thinking in a sample of students. Negative and positive thinking all seem to be related to the level of mental health. However, negative thinking is one of the strongest correlations with mental health levels in non-clinical students, whereas positive thinking is related to lower levels of anxiety and depression. Future research should clarify which is most effective in improving mental health: restructuring negative thinking, enhancing positive thinking, or restricting negative thinking and enhancing positive thinking.

\section{Disclosure of interest}

The authors declare that they have no competing interest.

\section{References}

[1] Ingram RE, Kendall PC, Siegle G, Guarino J. Psychometric properties of the positive automatic thoughts questionnaire. Psychol Assess 1995;7:495-507.

[2] Beck AT. Cognitive therapy and the emotional disorders. New York: The New American Library; 1976.

[3] Hollon SD, Kendall PC. Cognitive self-statements in depression: development of an automatic thoughts questionnaire. Cognit Ther Res 1980;4:383-95.

[4] Haaga DA, Dyck MJ, Ernst D. Empirical status of cognitive theory of depression [Review]. Psychol Bull 1991;110(2): 215-36.

[5] Kendall PC. Cognitive processes and procedures in behavior therapy. In: Wilson GT, Franks CM, Brownell KD, Kendall PC, editors. Annual review of behavior therapy: theory and practice. 9 New York: Guilford Press; 1984. p. 132-79.

[6] Kuiper NA, Derry PA. Depressed and non-depressed content self-reference in mild depressives. J Person 1982;50:67-80. 
[7] Heimberg RG, Acerra MC, Holstein A. Partner similarity mediates interpersonal anxiety. Cognit Ther Res 1985;9:443-53.

[8] Curwen B, Palmer S, Ruddell P. Brief cognitive behaviour therapy. London: Sage; 2000.

[9] Beck JS. Cognitive behavioral therapy: basics and beyond. 2nd ed. New York: Guilford Press; 2011.

[10] Hofmann SG, Asmundson GJ. Acceptance and mindfulnessbased therapy: new wave or old hat? Clin Psychol Rev 2008;28(1):1-16.

[11] Beck AT, Rush AJ, Shaw BF, Emery G. Cognitive therapy of depression. New York: Guilford Press; 1979.

[12] Deacon BJ, Fawzy TI, Lickel JJ. Cognitive defusion versus cognitive restructuring in the treatment of negative self-referential thoughts: an investigation of process and outcome. J Cogn Psychother 2011;25(3):218-32.

[13] Lightsey OR. "Thinking positive'” as a stress buffer: the role of positive automatic cognitions in depression and happiness. J Consult Psychol 1994;41:325-34.

[14] Lightsey OR. Positive automatic cognitions as moderators of the negative life event-dysphoria relationship. Cognit Ther Res 1994; 18:353-65.

[15] Muris P, Mayer B, den Adel M, Roos T, van Wamelen J. Predictors of change following cognitive-behavioral treatment of children with anxiety problems: a preliminary investigation on negative automatic thoughts and anxiety control. Child Psychiatry Hum Dev 2009;40(1):139-51.

[16] Burgess E, Haaga OA. The positive automatic thoughts questionnaire (ATQ-P) and the automatic thoughts questionnairerevised (ATQ-RP): equivalent measures of positive thinking? Cognit Ther Res 1994;18:15-23.

[17] Wong SS. Negative thinking versus positive thinking in a Singaporean student sample: relationships with psychological well-being and psychological maladjustment. Learn Individ Differ 2012;22:76-82.

[18] McEvoy PM, Mahoney AE, Moulds ML. Are worry, rumination, and post-event processing one and the same? Development of the repetitive thinking questionnaire. J Anxiety Disord 2010;24(5):509-19.

[19] Beck AT, Emery G, Greenberg RL. Anxiety disorders and phobias: a cognitive perspective. New York: Basic Books; 1985.

[20] Wong SS. The relations of cognitive triad, dysfunctional attitudes, automatic thoughts, and irrational beliefs with test anxiety. Curr Psychol 2008;27:177-91.

[21] Hogendoorn SM, Prins PJ, Vervoort L, Wolters LH, Nauta MH, Hartman CA, et al. Positive thinking in anxiety disordered children reconsidered. J Anxiety Disord 2012;26(1):71-8.

[22] Beazley MB, Glass CR, Chambless DL, Arnkoff DB. Cognitive self-statements in social phobia: a comparison across three types of social situations. Cognit Ther Res 2001;25: 781-99.

[23] Kendall PC, Chansky TE. Considering cognition in anxietydisordered children. J Anxiety Disord 1991;5:167-85.

[24] Lightsey OR, Christopher JC. Stress buffers and dysphoria in a non-western population. J Couns Dev 1997;75:451-9.

[25] Ingram RE, Wisnicki KS. Assessment of positive automatic cognition. J Consult Clin Psychol 1988;56(6):898-902.

[26] Ingram RE, Price JM. Vulnerability to psychopathology: risk across the lifespan. 2nd ed. New York: Guilford Press; 2010.

[27] Seligman ME, Csikszentmihalyi M. Positive psychology. An introduction. Am Psychol 2000;55(1):5-14.

[28] Simonton DK, Baumeister RF. Positive psychology at the summit. Rev Gen Psychol 2005;9:99-102.

[29] Beck AT. The current state of cognitive therapy: a 40-year retrospective. Arch Gen Psychiatry 2005;62(9):953-9.

[30] Calvete E, Connor-Smith JK. Automatic thoughts and psychological symptoms: a cross-cultural comparison of American and Spanish students. Cognit Ther Res 2005;29(2):201-17.
[31] Kazdin AE. Evaluation of the Automatic Thoughts Questionnaire: negative cognitive processes and depression among children. Psychological assessment. J Consult Clin Psychol 1990;2(1):73-9.

[32] Harrell TH, Ryon NB. Cognitive-behavioral assessment of depression: clinical validation of the Automatic Thoughts Questionnaire. J Consult Clin Psychol 1983;51(5):721-5.

[33] Ghassemzadeh H, Mojtabai R, Karamghadiri N, Ebrahimkhani $\mathrm{N}$. Psychometric properties of a Persian-language version of the Automatic Thoughts Questionnaire: ATQ-Persian. Int J Soc Psychiatry 2006;52(2):127-37.

[34] Zettle RD, Webster BK, Gird SR, Wagener AL, Burdsal CA. Factor structure of the Automatic Thoughts Questionnaire in a clinical sample. Int J Cogn Ther 2013;6(3):280-91.

[35] Aydin KB. Automatic thoughts as predictors of Turkish university students' state anxiety. Soc Behav Pers 2009;37(8):1065-72.

[36] Netemeyer RG, Williamson DA, Burton S, Biswas D, Jindal S, Landreth S, et al. Psychometric properties of shortened versions of the Automatic Thoughts Questionnaire. Educ Psychol Meas 2002;62:111-29.

[37] Chioqueta AP, Stiles TC. Dimensions of the Dysfunctional Attitude Scale (DAS-A) and the Automatic Thoughts Questionnaire (ATQ-30) as cognitive vulnerability factors in the development of suicide ideation. Behav Cogn Psychother 2007;35:579-89.

[38] Whisman MA, Perez JE, Ramel W. Factor structure of the Beck Depression Inventory-Second Edition (BDI-II) in a student sample. J Clin Psychol 2000;56(4):545-51.

[39] Bruch MA, Mattia JL, Heimberg RG, Holt CS. Cognitive specificity in social anxiety and depression: supporting evidence and qualifications due to affective confounding. Cognit Ther Res 1993;17:1-21.

[40] Beck AT, Epstein N, Brown G, Steer RA. An inventory for measuring clinical anxiety: psychometric properties. J Consult Clin Psychol 1988;56(6):893-7.

[41] Zahn-Waxler C, Crick NR, Shirtcliff EA, Woods KE. The origins and development of psychopathology in females and males. In: Cicchetti D, Cohen DJ, editors. Developmental psychopathology: risk, disorder, and adaptation. Hoboken, New Jersey: Wiley; 2006. p. 76-138.

[42] Szentagotai A, Freeman A. An analysis of the relationship between irrational beliefs and automatic thoughts in predicting distress. J Cogn Behav Psychother 2007;7:1-9.

[43] Kendall PC, Hollon SD. Assessing self-referent speech: methods in the measurement of self-statement. In: Kendall PC, HolIon SD, editors. Assessment strategies for cognitive-behavioral interventions. New York: Academic Press; 1981. p. 85-118.

[44] Teasdale JD. Psychological treatments for depression: how do they work? Behav Res Ther 1985;23:157-65.

[45] Beck AT. Depression: clinical, experimental, and theoretical aspects. New York: Harper \& Row; 1967.

[46] Furlong M, Oei PST. Changes to automatic thoughts and dysfunctional attitudes in group CBT for depression. Behav Cogn Psychother 2002;30:351-60.

[47] Cuijpers P, van Straten A, Andersson G, van Oppen P. Psychotherapy for depression in adults: a meta-analysis of comparative outcome studies. J Consult Clin Psychol 2008;76:909-22.

[48] Dobson KS. A meta-analysis of efficacy of cognitive therapy for depression. J Consult Clin Psychol 1989;57:414-9.

[49] Butler AC, Chapman JE, Forman EM, Beck AT. The empirical status of cognitive-behavioral therapy: a review of meta-analyses. Clin Psychol Rev 2006;26(1):17-31.

[50] Kendall PC. Methodology and cognitive-behavioral assessment. Behav Cogn Psychother 1983;11:285-301.

[51] Abramson LY, Metalsky GI, Alloy LB. Hopelessness depression: a theory-based subtype of depression. Psychol Rev 1989;96:358-72. 
[52] Alloy LB. Cognitive processes in depression. New York: Guilford; 1988.

[53] Beck AT. Cognitive models of depression. J Cogn Psychother 1987;1:5-37.

[54] Tanaka N, Uji M, Hiramura H, Chen Z, Shikai N, Kitamura T. Cognitive patterns and depression: study of a Japanese university student population. Psychiatry Clin Neurosci 2006;60(3):358-64.
[55] Purdon C. Thought suppression and psychopathology. Behav Res Ther 1999;37(11):1029-54.

[56] Kopala-Sibley DC, Santor DA. The mediating role of automatic thoughts in the personality-event-affect relationship. Cogn Behav Ther 2009;38(3):153-61.

[57] Alsaleh M, Lebreuilly R, Lebreuilly J, Tostain M. Cognitive balance: states-of-mind model and mental health among French students. Best Pract Ment Health 2015;11(1):42-53. 